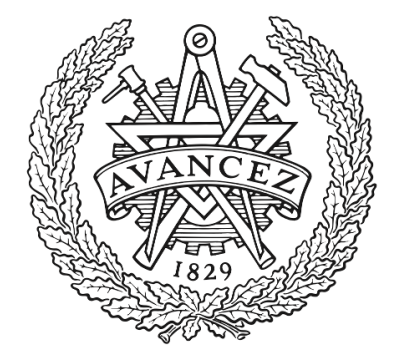

\title{
CHALMERS
}

UNIVERSITY OF TECHNOLOGY

\section{Effect of cultivation conditions on the structure and morphological properties of BNC biomaterials with a focus on vascular grafts}

Downloaded from: https://research.chalmers.se, 2023-04-26 10:10 UTC

Citation for the original published paper (version of record):

Gatenholm, P., Höglund, K., Johannesson, S. et al (2016). Effect of cultivation conditions on the structure and morphological properties of BNC biomaterials with a focus on vascular grafts. Bacterial NanoCellulose: A Sophisticated Multifunctional Material: 19-42. http://dx.doi.org/10.1201/b12936-3

N.B. When citing this work, cite the original published paper. 


\title{
Effect of Cultivation Conditions on the Structure and Morphological Properties of BNC Biomaterials with a Focus on Vascular Grafts
}

\author{
Paul Gatenholm, ${ }^{1}$ Kim Höglund, ${ }^{1}$ Sara Johannesson, ${ }^{1}$ Maja Puchades, ${ }^{1}$ \\ Christian Brackmann, ${ }^{2}$ Annika Enejder, ${ }^{2}$ and Lisbeth Olsson ${ }^{3}$ \\ ${ }^{1}$ Department of Chemical and Biological Engineering, \\ Biosynthetic Blood Vessel Laboratory, Biopolymer Technology, \\ Chalmers University of Technology, Gothenburg, Sweden \\ ${ }^{2}$ Department of Chemical and Biological Engineering, \\ Life Sciences, Molecular Microscopy, and Biotechnology, \\ Chalmers University of Technology, Gothenburg, Sweden \\ ${ }^{3}$ Department of Chemical and Biological Engineering, Industrial Biotechnology, \\ Chalmers University of Technology, Gothenburg, Sweden
}

\section{CONTENTS}

Introduction

Bacterial Cellulose Production: A Part of the Carbon Metabolism in

G. xylinus

Factors Involved during Nanocellulose Network Formation by G. xylinus ....24 Effect of Growth Medium Components on Bacterial Cellulose

Production in G. xylinus ........................................................................... 26

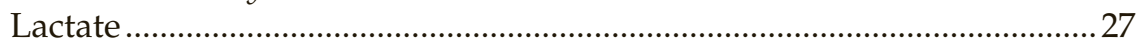

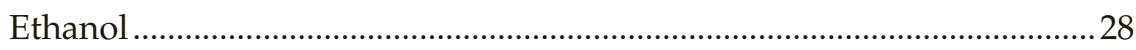

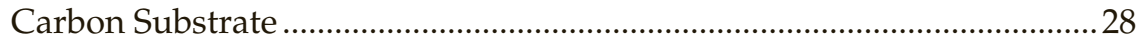

Corn Steep Liquor ................................................................................ 28

Genetic Modifications of G. xylinus for Enhanced Production of

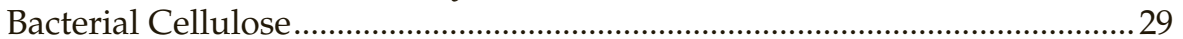

Transfection of G. xylinus with the pBla-VHb-122 Plasmid ......................29

Spontaneous Mutation in G. xylinus Can Lead to a Loss of the

Ability to Produce Cellulose ...................................................................... 30

Production of Artificial Blood Vessels by G. xylinus in Bioreactors ............... 31

Tube Bioreactor ............................................................................................... 32

Cellulose Production Yield and Cellulose Content ....................................35

Cellulose Content ...................................................................................... 36 
Influence of Oxygen Availability on Tube Formation................................36

Properties and Components of CSL ....................................................... 37

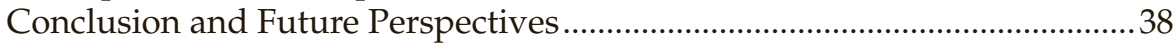

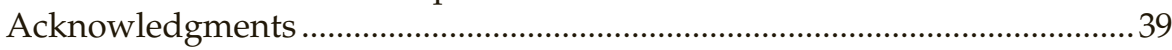

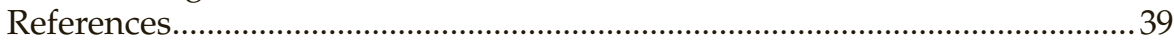

New materials that are not thrombogenic and have mechanical properties that mimic the native blood vessel are in very great demand. Nanocellulose produced by the bacteria Gluconacetobacter xylinus is a biomaterial that has gained interest in the field of tissue engineering because of its unique properties, such as great mechanical strength, high water content (around $99 \%$, and the ability to be shaped into three-dimensional structures during biosynthesis. The fabrication process of bacterial nanocellulose (BNC) vascular grafts is very unique because the material synthesis and product formation takes place simultaneously. The biomechanical performance, which includes rupture pressure and compliance along with biological response (endothelialization, blood compatibility, etc.), is dependent on the morphology of a fibrillar network. The network formation is affected by cellulose assembly and bacteria motion, proliferation rate, and other factors. An understanding of the effects of cultivation conditions on BNC network formation is therefore of great importance.

\section{Introduction}

The network of cellulose nanofibrils produced by the acetic acid bacteria Gluconacetobacter xylinus creates a biomaterial with great mechanical strength, high water content (around 99\%), and the ability to be shaped into three-dimensional (3D) structures during biosynthesis. Cultivation can be done in the presence of molds and porogens of different sizes and shapes, which makes it possible to design desirable biomaterial geometries. Bacterial nanocellulose (BNC) has been used in wound healing applications (Wei et al. 2011; Zhang et al. 2010), cartilage repair (Svensson et al. 2005), bone regeneration (Zaborowska et al. 2010), and most recently, for blood vessel replacements (Wippermann et al. 2009). The focus of this review will be on the development of tubular cellulose scaffolds for use as small-caliber artificial blood vessels (see Figure 2.1).

Cardiovascular disease is the major cause of death and morbidity in Western countries. Surgical bypass with autologous grafts remains the most used treatment. However, many patients in need of reconstruction of their vascular system, either in the heart, lower extremities, or other locations, do not have suitable vessels due to preexisting vascular disease or amputation. Approximately $5 \%-10 \%$ of all patients that need coronary bypass need a good 


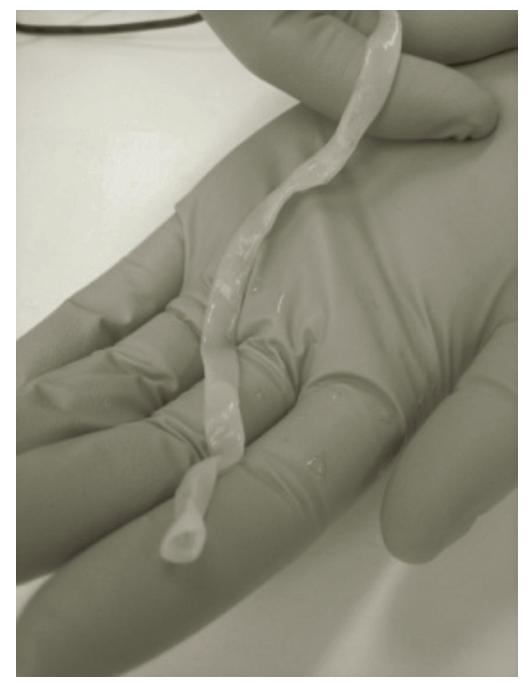

FIGURE 2.1

(See color insert.) An artificial blood vessel synthesized by the bacteria G. xylinus.

replacement for their own autologous grafts. Today it is possible to replace large arteries with synthetic grafts (e.g., Dacron, expanded polytetrafluoroethylene [ePTFE], and polyurethane). However, these materials give poor performance for small (less than $6 \mathrm{~mm}$ ) grafts due to the formation of thrombosis and occlusion (Hess et al. 1985). New materials that are not thrombogenic and have mechanical properties that mimic the native blood vessel are needed. Nanocellulose produced by G. xylinus is a biomaterial that has gained interest in the field of tissue engineering owing to its unique properties (i.e., great mechanical strength, high water content, and the ability to be shaped into 3D structures during biosynthesis). Cultivation can be done in the presence of molds and porogens of different sizes and shapes, making it possible to design desirable scaffold geometries (Bäckdahl et al. 2008; Bodin et al. 2007). Several generations of bioreactors have been designed and constructed to grow BNC tubes. Bioreactors have been designed and fermentation conditions developed that allow the growth of tubes in various diameters and lengths $(1-10 \mathrm{~mm}$ in diameter, 4-30 cm in length) as well as in various shapes. Several techniques to alter the porosity of BNC are currently under investigation.

The fabrication process of BNC vascular grafts is very unique because the material synthesis and product formation take place simultaneously. The biomechanical performance, including rupture pressure and compliance along with biological response (endothelialization, blood compatibility, etc.), is dependent on the morphology of the fibrillar network. The network formation is affected by cellulose assembly and bacteria motion, proliferation rate, and other factors. An understanding of the effects of cultivation conditions on BNC network formation is therefore of great importance. 


\section{Bacterial Cellulose Production: A Part of the Carbon Metabolism in G. xylinus}

The production of BNC in G. xylinus is a part of its carbon metabolism (Figure 2.2). Depending on the main carbon source used in the growth media, different initial pathways toward the central metabolites, $x$ and $y$, are used. The initial pathways for fructose and glucose are separate, but both lead to the central carbon metabolite glucose-6-phosphate (Figure 2.2).

G. xylinus can use carbon sources such as manitol, glycerol, sucrose, and galactose, in addition to glucose and fructose (Mikkelsen et al. 2009). When G. xylinus is cultivated in glucose- or sucrose-based media, 2- and 5-ketogluconate acids are produced by the conversion of glucose into gluconate by the enzyme glucose oxidase. The production of ketogluconate acids lowers the yield of BNC produced and contributes to a decrease in $\mathrm{pH}$. De Wulf et al. (1996) demonstrated that G. xylinus mutants, restricted in ketogluconic acids synthesis, are able to produce more BNC compared to wild-type G. xylinus.

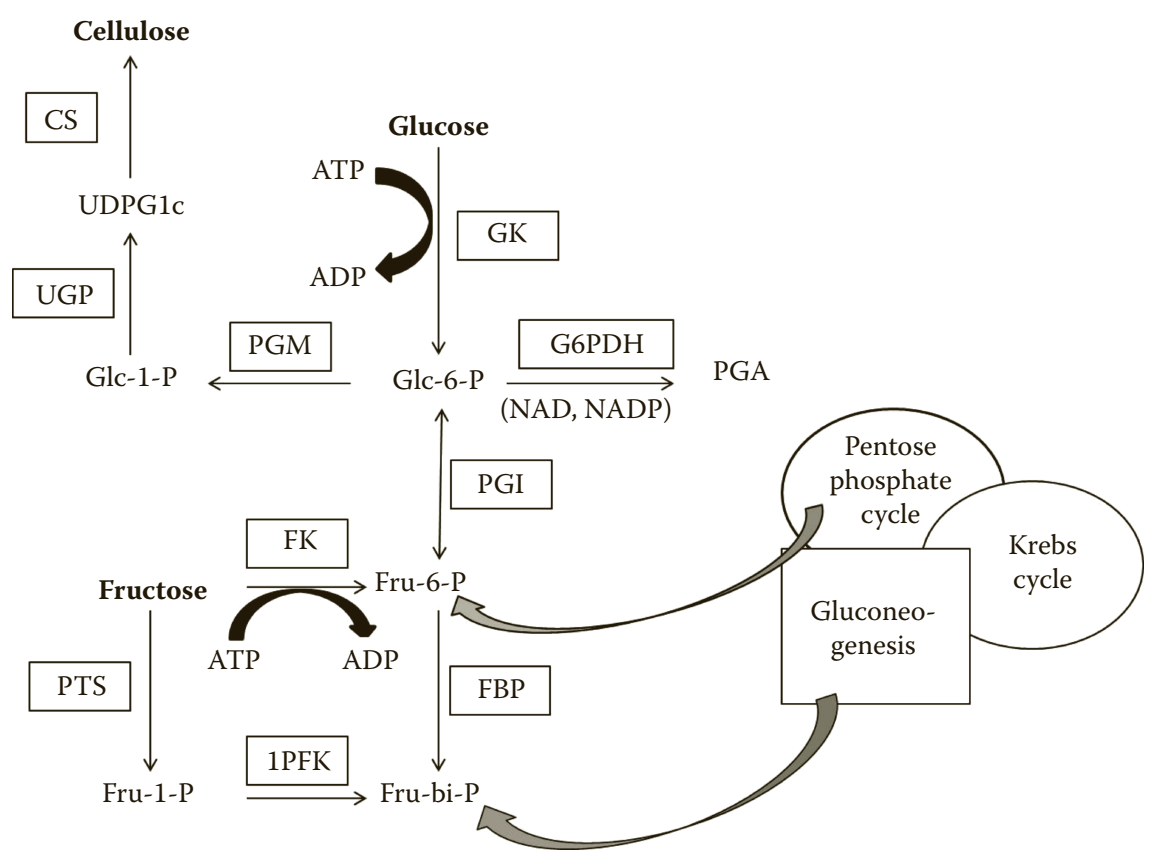

FIGURE 2.2

Illustration of the carbon metabolism in G. xylinus. Figure adapted from Ross et al. (1991). CS: cellulose synthase; FBP: fructose-1,6-biphosphate phosphatase; FK: glucokinase; G6PDH: glucose-6-phosphate dehydrogenase; 1PFK: fructose-1-phosphate kinase; PGI: phosphoglucoisomerase;PGM: phosphoglucomutase; PTS: system of phosphotransferases; UGP:pyrophosphorylase UDPGlc; Fru-bi-P: fructose-1,6-bi-phosphatase; Fru-6-P: fructose-6-phosphate; Glc-6(1)-P: glucose-6(1)phosphate; PGA: phosphogluconic acid; UDPGlc: uridine diphosphoglucose. 
This further supports the fact that the formation of ketogluconic acids is not optimal for BNC production. If fructose is used as the carbon source in growth media, only cellulose, acetan, and carbon dioxide are produced (Ross et al. 1991). Studies have shown that fructose utilization is suppressed when G. xylinus is cultivated in glucose-based growth media, which is not the case in sucrose-based media. This is probably because glucose has an inhibitory effect on fructokinase via the competition with fructose. Glucose is therefore physiologically significant, as it may serve as a sensitive regulatory mechanism (Benzamin and Rivertz 1972). On the other hand, glucose can be utilized as a substrate even if fructose or sucrose is added to the growth media as the main carbon source (Benzamin and Rivertz 1972).

The initial metabolic steps in the fructose and glucose utilization pathways are initially different, whereas, from glucose-6-phosphate and further, the same metabolic pathway is followed for BNC production. Glucose is taken up by the bacteria and transformed into glucose-6-phosphate by glucokinase. Fructose, on the other hand, is first phosphorylated into fructose- 6 phosphate by fructokinase and thereafter transformed into glucose-6-phosphate by phosphoglucoisomerase. Glucose-6-phosphate is transformed via isomerization into glucose-1-phosphate by phosphoglucomutase followed by transformation of glucose-1-phosphate into uridine diphosphate glucose (UDP-glucose) by pyrophosphorylase UDPGlc (Ross et al. 1991). G. xylinus mutants that are cellulose negative $\left(\mathrm{Cel}^{-}\right)$lack pyrophosphorylase UDPGlc and can therefore not produce UDP-glucose and BNC, since UDP-glucose is a crucial intermediate for cellulose synthesis (Krystynowicz et al. 2005). The organization of cellulose synthase in the membrane is important for regulating diverse cellular functions, including motility, biofilm formation, cell cycle progression, and virulence in bacteria. Cellulose synthase is regulated by the cyclic nucleotide bis- $\left(3^{\prime}, 5^{\prime}\right)$-cyclic dimeric guanosine monophosphate (c-di-GMP), which acts as a reversible allosteric activator for the enzyme; that is, when c-di-GMP binds cellulose synthase (at a site distant to the active site), it enhances the activity of the enzyme. The concentration of c-di-GMP is in turn regulated by diguanylate cyclase, which activates c-di-GMP and phosphodiesterase A and B (PDE-A and PDE-B) that degrade c-di-GMP. The degradation mechanism of c-di-GMP by PDE-A and PDE-B is still unclear (Ross et al. 1990). PDE-A is $\mathrm{Ca}^{2+}$ sensitive and studies have concluded that PDE-A is inhibited by $\mathrm{Ca}^{2+}$ since $\mathrm{Ca}^{2+}$ is suggested to compete for a binding site with $\mathrm{Mg}^{2+}$, which is required for the PDE-A activity (Ross et al. 1990). More recent studies have also demonstrated that PDE-A is negatively regulated by oxygen due to a heme-containing domain that binds oxygen reversibly (Chang et al. 2001). The regulating process is not fully understood and investigations are ongoing to unravel the full regulating process of cellulose synthase.

Many other enzymes and regulatory mechanisms are involved in the carbon metabolism of G. xylinus and only a fraction of them have been mentioned here since the focus of this review is BNC production and not the metabolism of bacteria in general. 


\section{Factors Involved during Nanocellulose Network Formation by G. xylinus}

There are different theories about the role of cellulose production by G. xylinus, which results in a nanocellulose network. The cellulose is believed to prevent the bacteria from dehydrating and also helps the bacteria to become floatable, via entrapment of carbon dioxide (produced from the tricarboxylic acid [TCA] cycle). This helps the bacteria to reach the air-liquid interface, an important issue since the bacteria is an obligate aerobe (Schramm and Hestrin 1954). The cellulose biofilm is also a natural way of immobilizing the bacteria and helps it attach to the surface (Cook and Colvin 1980). Moreover, the biofilm has been shown to protect the bacteria from ultraviolet (UV) light to some extent (Williams and Cannon 1989). Many external factors affecting the morphology of the nanocellulose network and the production rate of cellulose exist. Oxygen is one important factor, demonstrated by Watanabe and Yamanaka (1985) in their study, where they show that oxygen tension has a great influence on the cellulose network produced. Oxygen tension greater than $40 \%$ results in a higher growth rate of G. xylinus as compared to when the bacteria are cultured at oxygen tensions of less than 15\% (Watanabe and Yamanaka 1985).

The branching of the nanocellulose network is affected by the proliferation rate of G. xylinus (Figure 2.3A) (Yamanaka et al. 1989), which is in turn dependent on the oxygen tension (Figure 2.3B) (Watanabe and Yamanaka 1985) and affects the density of the cellulose network produced.

Prior to cell division, the catalytic sites for cellulose production are doubled and activated directly after division. No breakage of the cellulose ribbon occurs after division, just the creation of a branching point (Figure 2.3A) (Watanabe and Yamanaka 1985). When the dissolved oxygen tension is around 50\% of atmospheric pressure, a denser nanocellulose network is produced; if a lower oxygen tension is applied, the cellulose network becomes less dense (Figure 2.3B). Watanabe and Yamanaka found that the cellulose content increased as the oxygen tension increased. The opposite was found for lower oxygen tension, causing a decrease in the cellulose content. This phenomenon is probably due to the cell division rate of the bacteria, as a correlation between oxygen tension and cellulose network density was observed. Therefore the thickness of the cellulose membrane is only affected by the branching of the network, not by an increased width of the cellulose fibrils produced (Watanabe and Yamanaka 1985).

The degree of polymerization (DP) is the number of repeated units in a polymer, which in cellulose is D-glucose. The mechanism for development of the DP has been suggested to follow a Poisson distribution, which means that all molecules have the same probability to be added to the growing glucan chain. The DP in BNC is relatively high, around 2000-4000 (Marx-Figini and Pion 1974), whereas the cultivation conditions can have an impact on the DP of the produced cellulose. In an agitated culture of G. xylinus, the DP of the cellulose 


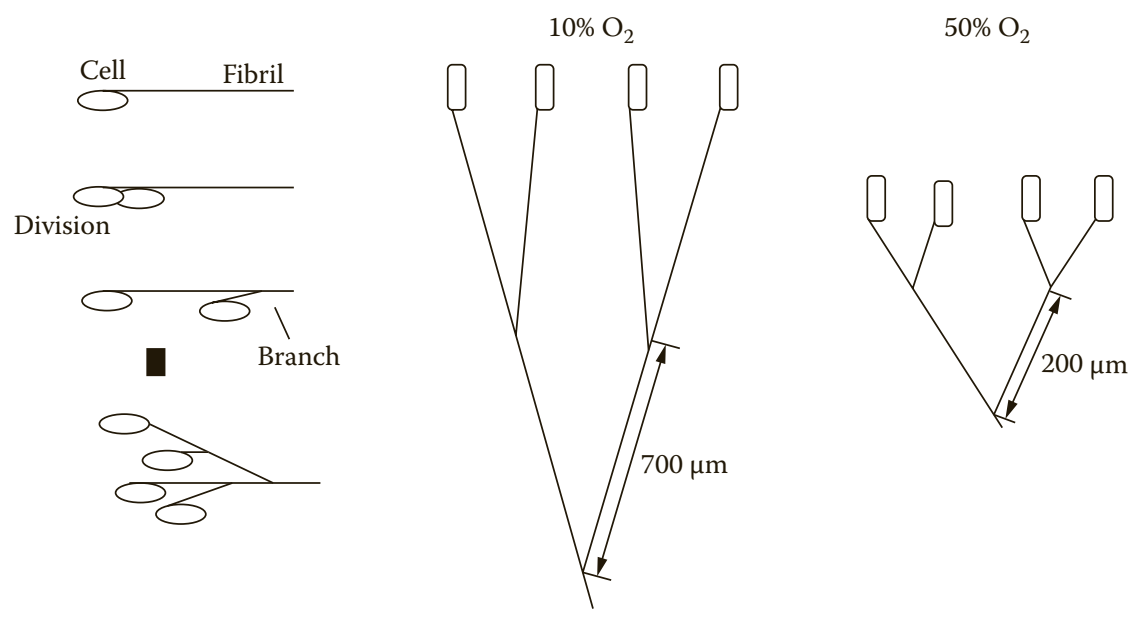

(a)

(b)

\section{FIGURE 2.3}

(a) The branching of cellulose formed by the cell division of G. xylinus. Adapted from Yamanaka et al. (1989). (b) The effect of oxygen tension on the branching of cellulose in the cellulose network formed during cell division. Adapted from Watanabe and Yamanaka (1985).

produced is lower than for cellulose produced in a static culture. The decrease in DP can be due to an increase in the activity of endoglucanases in agitated cultures (Czaja et al. 2004). Previous studies have shown that endoglucanases can have an effect on decreased DP in the long term (Tahara et al. 1997a, 1997b). Okajima et al. (1991) explained the phenomena of decreased DP as a function of cultivation time and generation time of the bacteria, not an effect of enzymes.

The $\mathrm{pH}$ is also an important factor for cellulose production and should be controlled and regulated during cultivation of G. xylinus. The $\mathrm{pH}$ outside the bacteria affects the structure and permeability of the bacteria cell membrane, which can have an effect on cellulose production and network formation. Verschuren et al. (2000) demonstrated that an optimal $\mathrm{pH}$ for BNC production is between $\mathrm{pH} 4$ and 5, which is in accordance with Noro et al. (2004), who describe that $\mathrm{pH} 4.5$ is optimal for BNC production. A cultivation $\mathrm{pH}$ below 3.5 results in no production of cellulose and the proliferation of the bacteria is negatively affected (Embuscado et al. 1994). However, the bacteria has been shown to be able to recover from exposure to low $\mathrm{pH}$ following 8 days in optimal growth conditions (i.e., in this case a higher $\mathrm{pH} ; \mathrm{pH} 4-5)$ (Embuscado et al. 1994).

The cellulose network production is also affected by the production of watersoluble polysaccharides such as acetan (Figure 2.4A) and levan (Figure 2.4B). Depending on which carbon substrate is used-glucose, fructose, or sucrosedifferent amounts of water-soluble polysaccharides are produced. No levan is produced in fructose- and glucose-based media, and in a sucrose-based media, levan is produced in a smaller amount than acetan. The greatest amount of water-soluble polysaccharides produced has been observed when G. xylinus is 

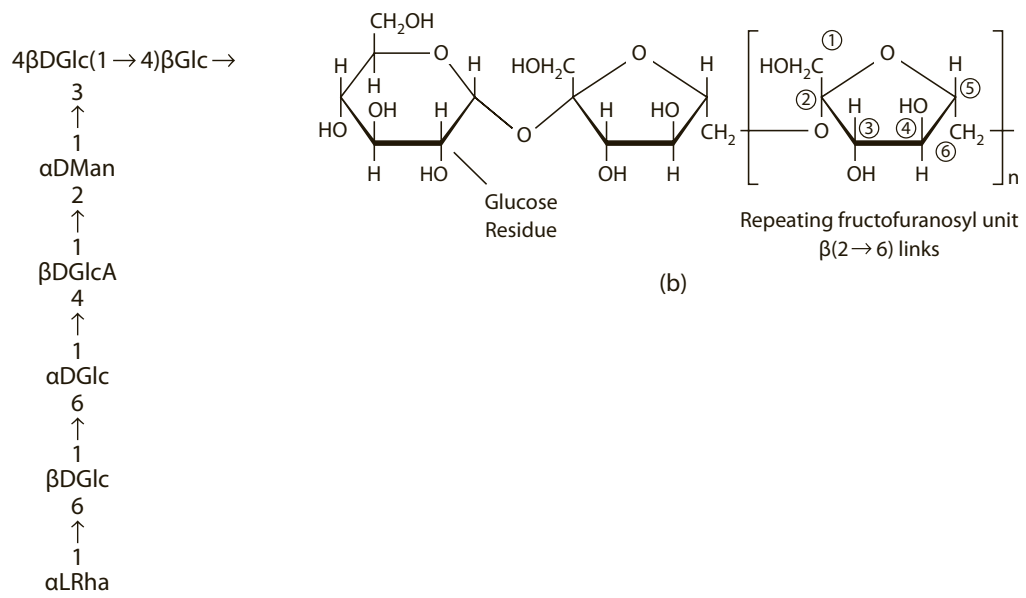

(b)

(a)

\section{FIGURE 2.4}

(a) Acetan: Glc = glucose; Man = mannose; GlcA = glucuronic acid; Rh = rhamnose. Adapted from Kirby et al. (1995). (b) Levan. Adapted from Arvidson et al. (2006).

grown in the presence of sucrose and the least when grown in the presence of glucose, depending on the formation of ketogluconate acids.

The production of these polysaccharides can differ, especially between mutants and wild-type strains of G. xylinus. The accumulated polysaccharides interfere with the cellulose crystallization process by preventing hydrogen bonding between the produced microfibrils (Watanabe et al. 1998).

Ishida et al. (2002) investigated a mutant of G. xylinus, EP1, that was not able to produce acetan. The hypothesis is that this mutant therefore should produce more BNC, since more of the carbon source can be used for BNC production. The outcome was the opposite, however; the mutant produced less BNC than the wild-type G. xylinus, which was used as a reference. When acetan was added to the cultivation medium for the EP1 mutant strain, BNC production was stimulated and the final yield was almost equal to the yield of the wild-type strain. The same phenomenon was seen when agar was added to the cultivation medium. The conclusion that can be drawn from these results is that the production of cellulose is dependent on how viscous the cultivation medium is during cultivation (Ishida et al. 2002).

\section{Effect of Growth Medium Components on Bacterial Cellulose Production in G. xylinus}

The growth media components have a great impact on BNC production in terms of cellulose production rate, yield, and network structure. The 


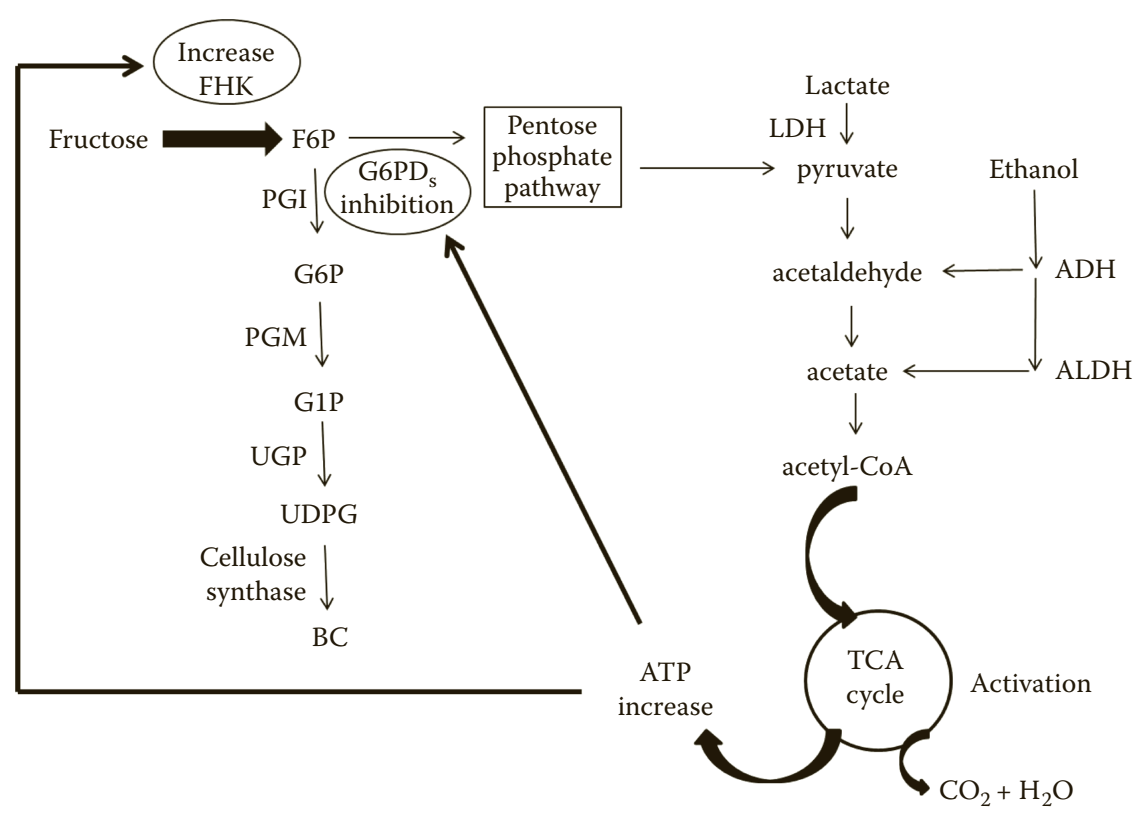

FIGURE 2.5

Effect of ethanol on bacterial cellulose production in continuous culture from fructose. Adapted from Naritomi et al. (1998).

components of the growth medium will increase the BNC production rate and yield and are often used by the bacteria as energy sources, not as a substrate for BNC production. Compounds that increase the production of water-soluble extracellular polysaccharides will probably affect the cellulose network, since the assembly of the cellulose chains is affected by the interference of water-soluble extracellular polysaccharides. Other compounds in the growth media can have an effect on the enzymes that are involved in the pathway where BNC is produced. The presence of a rapidly utilized carbon source in the growth media can lead to higher adenosine-5'-triphosphate (ATP) production, and ATP has an inhibitory effect on the enzyme glucose6-phosphate dehydrogenase (Figure 2.5).

\section{Lactate}

The addition of lactate to the growth media increases the cellulose production in G. xylinus since it is linked to the respiratory chain. Lactate generates energy and does not act as an extra substrate for cellulose production. This extra energy source provided by lactate increases the concentration of bacteria (i.e., biomass) during the early stages of cultivation, resulting in increased BNC production. Adding more lactate to the growth media will result in an increase in ATP production. A correlation between a high ATP level and a high specific 
BNC production rate has been found (Naritomi et al. 1998). This phenomenon is probably due to the activity of fructokinase being enhanced by ATP and the fact that ATP inhibits the enzyme glucose-6-phosphate dehydrogenase (Figure 2.5). This enzyme is a key enzyme that shuffles glucose-6-phosphate into the pentose phosphate pathway (Kornmann et al. 2003).

\section{Ethanol}

The oxidation of ethanol has the potential to produce extra energy for the bacteria in a similar way as lactate (Figure 2.5). However, the effect of adding ethanol to the growth medium is not as great as for the addition of lactate, which probably depends on the fact that the oxidation of ethanol produces higher levels of acetate. A high concentration of acetate has a negative effect on the bacteria, which is also true for acetic acid bacteria. The ethanol must be completely oxidized before the oxidation of acetate can start and an increase in biomass can be observed. The conclusion is that ethanol can increase BNC production via higher energy production, but not as efficiently as lactate due to the delay of biomass production (Kornmann et al. 2003; Matsuoka et al. 1996).

\section{Carbon Substrate}

The concentration of the carbon source has also been shown to affect the rate of cellulose synthesis, and when the substrate concentration increases, the utilization of the substrate decreases. Therefore an optimal level of substrate is needed to obtain high, consistent cellulose production throughout the cultivation (Embuscado et al. 1994). Regardless of the carbon source used, there are two different main phases according to Kornmann et al. (2003). In the first phase, biomass is produced and acetate oxidation occurs. The second phase begins when all the acetate is oxidized and only sugar is assimilated (Kornmann et al. 2003).

\section{Corn Steep Liquor}

Corn steep liquor (CSL) can be used as a component of complex microbial growth media. CSL contains different amino acids where methionine is the essential one (Matsuoka et al. 1996). Methionine stimulates growth of the bacteria during the early stages of cultivation and also reduces the lag time. An addition of different amino acids, including methionine, to the culture medium has been shown to induce an increase in cellulose production. The same increase in cellulose production has been observed when only methionine is added to the medium, clearly demonstrating that methionine is an important component of CSL. Methionine increases biomass production during the early stages of cultivation, which in turn has a positive effect on BNC production (Matsuoka et al. 1996). Amino acids together with ammonium in CSL account for more than $95 \%$ of the total 
nitrogen concentration (Cardinal and Hedrick 1947) and can be used as a nitrogen source in culture media for microorganisms. Different CSL batches have been shown to differ in total nitrogen and lactic acid content (Noro et al. 2004), which can have a great impact on the production of BNC. According to Noro et al., $40 \mathrm{~mL} \mathrm{CSL/L}$ growth media is the optimal concentration for optimal buffering capacity. With $40 \mathrm{~mL} / \mathrm{L}$ CSL, the $\mathrm{pH}$ was shown to stay constant at 4.5 during the whole cultivation time, which also seemed to be optimal for BNC production (Noro et al. 2004). This is in accordance with Verschuren et al. (2000) showing that the optimal pH for $\mathrm{BNC}$ production is between $\mathrm{pH} 4$ and 5. Moreover, Verschuren et al. used three different batches of CSL in their study and concluded that $\mathrm{pH}$ was the factor that affected cellulose production, since the amount of nitrogen, lactic acid, and fructose, respectively, were set to the same concentrations in all three CSL batches.

\section{Genetic Modifications of G. xylinus for Enhanced Production of Bacterial Cellulose}

Genetic modification of G. xylinus may be a way to increase BNC production. Environmental factors such as nutrient limitations and other factors such as stirring during cultivation and oxygenation can induce spontaneous mutations of the bacteria, which thereby may lose the ability to produce cellulose.

\section{Transfection of G. xylinus with the pBla-VHb-122 Plasmid}

The bacteria Vitreoscilla, discovered by E. G. Pringsheim in 1951, is a Gramnegative and obligate aerobe bacterium that lives in a microaerobic environment. During evolution these bacteria developed a way to utilize oxygen more efficiently. This occurs via the expression of bacterial hemoglobin, whose primary function is to enhance respiration in the bacteria. Vitreoscilla hemoglobin $(\mathrm{VHb})$ enhances respiration by capturing oxygen and facilitates the transfer of oxygen to the terminal oxidase (Tsai et al. 1996). The gene, vgb, encoding the hemoglobin in Vitreoscilla was isolated, sequenced, and characterized in 1988 by Dikshit and Webster, and has successfully been expressed in different heterologous hosts, such as Escherichia coli (Chien et al. 2006). The expression of the gene in E. coli enhances growth and product formation. The plasmid has successfully been amplified in E. coli and introduced into G. xylinus by electroporation (Setyawati et al. 2007). Chien et al. (2006) demonstrated that the expression of $\mathrm{VHb}$ enhances BNC production in G. xylinus. G. xylinus expressing $\mathrm{VHb}(\mathrm{VHb}+)$ have a higher specific growth rate under both aerobic and anaerobic conditions. The $\mathrm{VHb}+$ bacteria exhibited no obvious lag phase 
compared to $\mathrm{VHb}$ - bacteria (no $\mathrm{VHb}$ expression) with a lag time of 6 hours. This is probably due to an increased efficiency of oxygen uptake in the bacteria caused by the hemoglobin. Differences have also been observed between $\mathrm{VHb}+$ and $\mathrm{VHb}-$ in static cultures under normal oxygen conditions. Under microaerobic conditions, $\mathrm{VHb}$ expression was shown to enhance cellulose production two-fold. It is speculated that the increased production of BNC is dependent on increased production of ATP and that the glucose could be used for BNC production instead of ATP synthesis (Chien et al. 2006). This assumption is based on the findings, demonstrated in E. coli, where $\mathrm{VHb}$ expression enhances respiratory activity and increases ATP production.

\section{Spontaneous Mutation in G. xylinus Can Lead to a Loss of the Ability to Produce Cellulose}

G. xylinus is prone to spontaneous mutations sometimes resulting in a reduced or lost ability to produce cellulose $\left(\mathrm{Cel}^{-}\right)$. This type of mutation was first described by Schramm and Hestrin in 1954 and is more common in agitated and aerated cultures than in static cultures. Schramm and Hestrin found three different types of G. xylinus: the first type was the G. xylinus wild-type strain that produced cellulose (Cel+) and the other two were low producers of cellulose $\left(\mathrm{Cel}^{-}\right)$. To prevent mutation of G. xylinus in agitated cultures, ethanol can be added to the cultivation medium (Son et al. 2001). There are several other studies of G. xylinus mutations and different properties of the mutants have been discovered. Valla and Kjosbakken (1982) reported the probability of an indirect connection between cellulose production and the production of a soluble extracellular polysaccharide in $\mathrm{Cel}^{-}$mutants, since these produce large amounts of extracellular polysaccharides, such as acetan. In the same study it was also demonstrated that $\mathrm{Cel}^{-}$mutants grow faster than cellulose-producing cells. Furthermore, according to Valla et al. (1987), the plasmids by themselves can also be involved in cellulose production, since many mutants have demonstrated changes in their plasmid DNA profile in comparison with the wild-type G. xylinus strain. The mechanism is difficult to understand clearly since G. xylinus has a complex system of plasmids (Rezaee et al. 2005). One explanation may be that the $\mathrm{Cel}^{-}$bacteria lack two enzymes, phosphoglucomutase and glucose-1-phosphate uridylyltransferase (Krystynowicz et al. 2005), which are both key enzymes in cellulose production in G. xylinus. Moreover, spontaneous mutations of G. xylinus into $\mathrm{Cel}^{-}$can be caused by insertion sequences (ISs). Movement of the IS can lead to inactivation of genes involved in the cellulose synthesis. $\mathrm{Cel}^{-}$mutants have been shown to have two or more IS elements and their DNA appears to be rearranged within the IS element. This was not the case for Cel+ G. xylinus (Coucheron 1991).

In $\mathrm{Cel}^{-}$mutants three enzymes were shown to be upregulated while two were downregulated, as demonstrated by Nguyen et al. (2010). One of the upregulated enzymes was deoxythymidine diphosphate (dTDP)-4-dehydrorhamnose 3,5-epimerase, which can be associated with a decrease in cellulose 
production in the mutant strain. This is probably due to the presence of dTDP rhamnose produced by the enzyme. The enzyme can activate acetan synthesis, which in turn reduces the production of cellulose. The same study also demonstrated that the enzyme dTDP-4-dehydrorhamnose 3,5-epimerase was absent in wild-type G. xylinus. Another mutant of G. xylinus, K3, has been shown to produce a cellulose network that is less dense than the one produced by wild-type G. xylinus. Investigations of the cellulose produced by wild-type G. xylinus and the K3 mutant were performed with nuclear magnetic resonance (NMR) and scanning electron microscopy (SEM), demonstrating the same crystalline structure. However, the difference between the wild-type G. xylinus and the mutant K3 appeared to be in their protein profiles (Nguyen et al. 2010).

Moreover, Nguyen et al. (2010) noticed that in some of their static cultures, the produced cellulose pellicle sank to the bottom of the culturing flask. After investigations of the pellicle with SEM, it was shown that the pellicle consisted of a looser cellulose network as compared with wild-type G. xylinus. Further investigations with NMR demonstrated that the cellulose network produced was cellulose I, which is the same type of cellulose that is produced by wild-type G. xylinus (Nguyen et al. 2010).

G. xylinus can be cultivated in static, agitated, or aerated conditions, and different strains of the bacteria are used depending on the cultivation conditions. The G. xylinus strain is prone to spontaneously mutate, whereas the special strain NQ5 of G. xylinus has a more stable genome and is therefore often preferable in agitated and aerated bioreactors (Brown and Lin 1990; Saxena et al. 1990).

As described earlier, there are differences between the wild-type G. xylinus and mutants of G. xylinus. In order to get a better understanding of the bacteria and its cellulose production these mutants need to be studied in more detail, since the mutants can give important information on regulatory mechanisms followed by changes in their environment. Even if spontaneous mutations easily occur in G. xylinus, natural changes in their metabolism, due to changes in the environment of the bacteria, can also be a reason for changing the appearance of the produced cellulose.

\section{Production of Artificial Blood Vessels by G. xylinus in Bioreactors}

Synthetic grafts used today, such as polyester (Dacron) and ePTFE, induce thrombosis and therefore are not suitable for the replacement of smaller blood vessels with a diameter of less than $6 \mathrm{~mm}$ (Nerem and Seliktar 2001). Research into new novel materials is thus needed. Nanocellulose produced by a microorganism can be used as a biomaterial in surgical applications, such as tissue 
implants in skin treatment. Furthermore, cellulose produced by microorganisms can be shaped for the particular application in the production process, for example, in the shape of cylinders (White and Brown 1989). One of the first production methods for forming BNC into various shapes with G. xylinus was described and patented by Roberts et al. (1986) (European patent number 0186495). In this method an oxygen-permeable polymer is used, such as polyvinyl chloride (PVC). This oxygen-permeable polymer is in contact with oxygen, whereas the other side is in contact with the liquid phase, including the bacteria. The growth is performed under static conditions; for the production of hollow tubes, the cultivation medium with bacteria is transferred into an oxygen-permeable polymer tube so that the inner surface is in contact with the liquid phase and the outer surface of the polymer tube is in contact with the oxygen. Since the polymer is oxygen permeable, the oxygen diffuses through the tube and becomes available to the bacteria in the liquid phase.

In 1990 Yamanaka et al. developed and patented a method, similar to that of Roberts et al. (1986), for producing long, hollow microbial cellulose by culturing Acetobacter xylinum (renamed G. xylinus by Yamanaka) in a hollow, oxygen-permeable container composed of silicon, cellophane, etc. (European patent application EP0396344). This method produced a cellulose membrane with a thickness of 0.01-20 mm. In $2001 \mathrm{Klemm}$ et al. described a method for production of tube-shaped cellulose, $\mathrm{BASY} \mathrm{C}^{\circledR}$, for microsurgery with the use of G. xylinus (named in the article as A. xylinum). The method was specially designed for microsurgery applications for the replacement of blood vessels with a diameter of $1-3 \mathrm{~mm}$. The artificial graft of $\mathrm{BNC}$ is produced between cylindrical glass tubes, and the advantage of this method, compared with the Yamanaka model, is that the texture of the inner surface can be controlled. The cultivation is performed under static conditions with Hestrin-Schramm cultivation medium. The oxygen is supplied via a second opening to the air space in the bioreactor. The method is further described in their patent (U.S. patent WO2001061026).

\section{Tube Bioreactor}

Another type of bioreactor used for the production of artificial blood vessels as well as for the production of microporous scaffolds for bone regeneration (Bäckdahl et al. 2008; Zaborowska et al. 2010) was developed by Paul Gatenholm et al. (2010) (U.S. patent application 20100042197). In this bioreactor a silicone tube is used as a support and oxygen supply for G. xylinus. Since the bacteria are obligate aerobes, they are attracted to the silicon tube, where they start to grow and produce cellulose around the silicone tube, forming a tube-shaped cellulose vessel. The cellulose is produced at the outer surface of the silicone tube. The rate of oxygen supplied into the bioreactor can be controlled with the use of silicone tubing in a glass tube. The BNC tube produced has high mechanical resistance and high burst pressure (U.S. patent application 20100042197). This type of bioreactor is here referred to as "tube bioreactor" (Figure 2.6). 


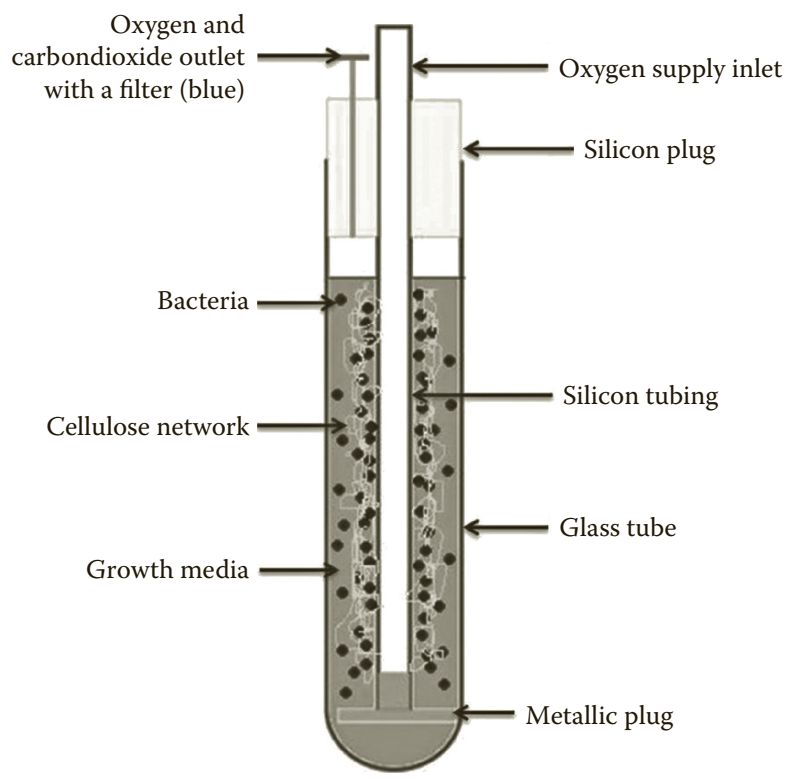

FIGURE 2.6

(See color insert.) Tube bioreactor setup for production of BNC vascular grafts. The bacteria, illustrated with black dots, produce the cellulose network, illustrated in beige, around the silicon tube.

$\mathrm{BNC}$ is an attractive material for vascular grafts due to its unique properties (great mechanical strength, high water content [approximately 99\%], good integration into host tissue, and flexibility of production in various shapes). The major challenge is to achieve the biomechanical properties required for long-term use as vascular grafts. The strain G. xylinus (ATCC 700178) is grown in a medium containing D-fructose, yeast extract, $\left(\mathrm{NH}_{4}\right)_{2} \mathrm{SO}_{4}, \mathrm{KH}_{2} \mathrm{PO}_{4}, \mathrm{MgSO}_{4} \cdot 7 \mathrm{H}_{2} \mathrm{O}, \mathrm{CSL}$, trace metal solution, and vitamin solution, and the $\mathrm{pH}$ is set to 5.5. Previous studies with the tube bioreactor have shown that G. xylinus synthesizes different cellulose layers with different densities, that is, a density gradient can be seen in the BNC tube produced (Bäckdahl et al. 2011). At the interface between these layers there is a tendency toward detachment (i.e., delamination). The production of two layers is desired, since they mimic two different types of extracellular matrix (ECM) in native connective tissue (Bäckdahl et al. 2011).

There is a clear difference between the two layers; the cellulose network closer to the lumen is denser and more ordered, whereas the layer far away from the lumen (i.e., closer to the cultivation medium) is less ordered and loose. The density gradient in the nanocellulose tube network produced can be clearly seen (Figure 2.7). Cross sections of cellulose vascular grafts produced after 4 days of cultivation (Figure 2.7A, magnification $\times 77$ ) and after 7 days of cultivation (Figure 2.7B, magnification $\times 130$ ) clearly show a density change in the cellulose network. The red ring (Figure 2.7A) represents a close-up (Figure 2.7C, magnification $\times 5000)$ at the interface between the two layers. 


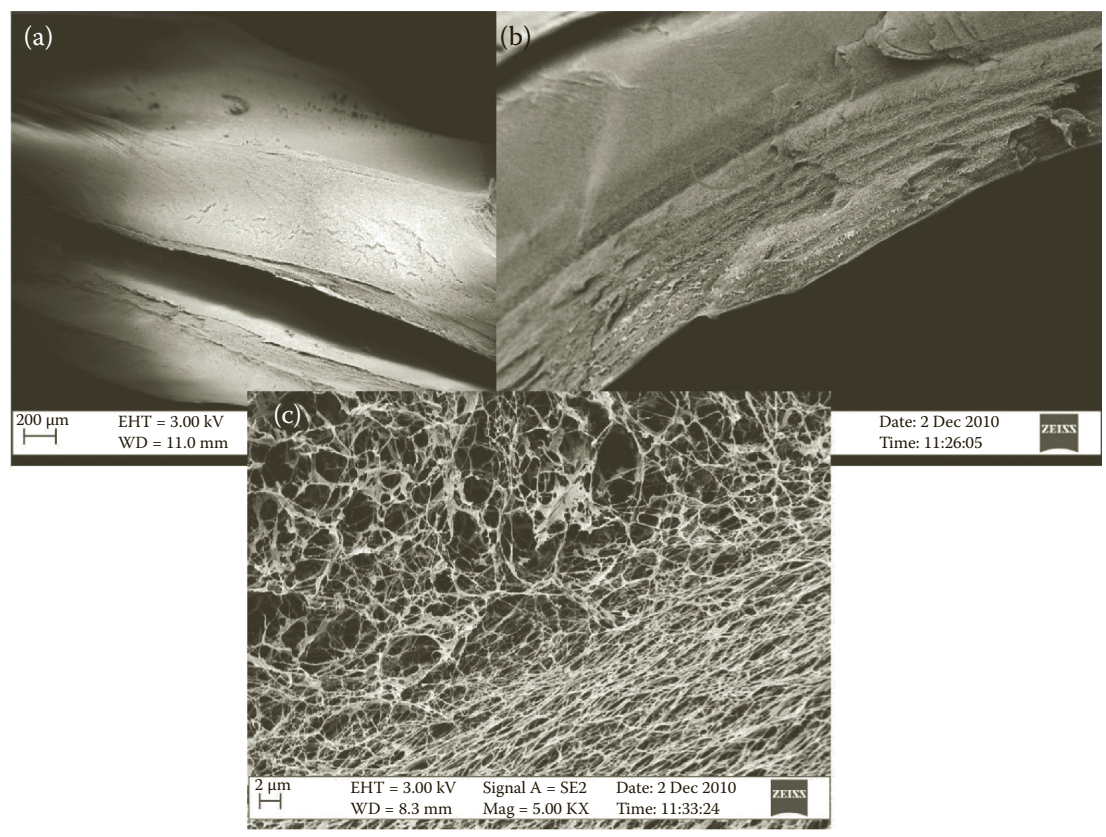

\section{FIGURE 2.7}

(a) Cross section of a cellulose tube after 4 days in culture (magnification $\times 77$ ). (b) Cross section of a cellulose tube after 7 days of cultivation (magnification $\times 130$ ). (c) Higher magnification of the red ring in (B) (magnification $\times 5000)$ illustrating the change in density in the cellulose network.

Density changes can be monitored as early as 2 days after culture, when a relatively stable tube structure has been formed. The gradient in the fiber network can be monitored by means of second harmonic generation (SHG) microscopy, which enables visualization of spun fibers as the ordered arrangement of glucose units in the cellulose polymer chains induces frequency-doubling of laser light illuminating the sample (Brackmann et al. 2010; Brown et al. 2003). Since this technique allows for measurements on wet unmodified samples taken directly from cultivation, it could be confirmed that the arrangement of cellulose into layers is a result of the synthesis process and not an artifact of the subsequent material purification procedure. The SHG image in Figure 2.8A, measured on a 2-day-old tube, shows a dense cellulose region of strong SHG signal (light gray color) located toward the luminal side of the tube (left), whereas less compact regions of cellulose (darker gray) can be found on the outer side. Simultaneously with the SHG measurements on the unpurified cellulose, the bacterial distribution in the material was visualized using coherent anti-Stokes Raman scattering (CARS) microscopy (Cheng 2007) (Figure 2.8B). The profile in Figure 2.8B, corresponding to the cellulose profile of Figure 2.8A, shows dense regions of bacteria in the inner regions of the tube, in particular the region of high cellulose fiber 


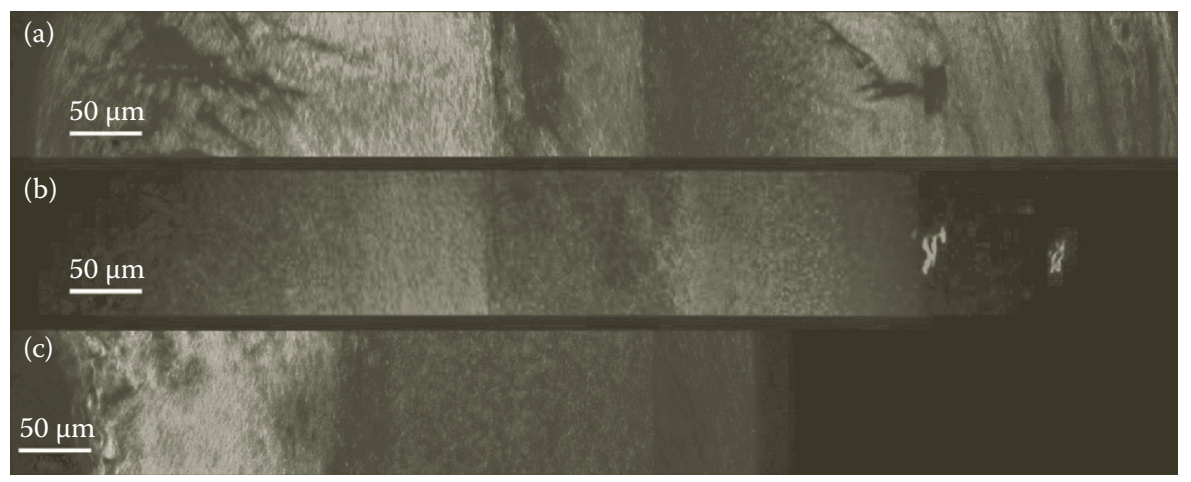

\section{FIGURE 2.8}

(See color insert.) Microscopy images showing radial distributions of cellulose fibers (blue, a and c) and G. xylinus (red, b) measured on 2-day-old tubes by SHG and CARS microscopy, respectively. Note the variations in cellulose density and SHG image intensity between regions on the inner luminal side (left) and outer side (right) observed for both a tube taken directly from cultivation (a) and a tube after purification (c).

density. A layered cellulose arrangement, with a dense region of high SHG signal at the luminal (left) side, can also be seen in the SHG image of Figure 2.8C, measured on a 2-day-old cellulose tube after material purification.

\section{Cellulose Production Yield and Cellulose Content}

The fructose level in the cultivation medium, before and after cultivation, and the cellulose dry weight were used to calculate the yield and production rate of bacterial cellulose (Table 2.1). The yield decreased during the 7 days of cultivation and the highest yield was obtained at day $1(2.402 \mathrm{~g} / \mathrm{g})$. This high yield is probably a result of the yield being calculated only for the fructose utilization and not the small amount of glucose present in the cultivation medium in the first 48 hours (Table 2.1).

\section{TABLE 2.1}

The Cellulose Production Yield is Presented in Both Grams of Bacterial Cellulose Obtained per Consumed Grams of Fructose and as Yield Obtained Per Day; pH 5.5.

\begin{tabular}{lcc}
\hline & $\begin{array}{c}\text { Yield p/s } \\
(\mathrm{g} / \mathrm{g})\end{array}$ & $\begin{array}{c}\text { Production Rate } \mathrm{p} / \mathbf{s} \\
(\mathrm{g} / \mathrm{g} / \text { day })\end{array}$ \\
\hline Day 1 & 2.402 & 2.402 \\
Day 2 & 0.541 & 0.271 \\
Day 3 & 0.183 & 0.061 \\
Day 4 & 0.145 & 0.036 \\
Day 7 & 0.141 & 0.02 \\
\hline
\end{tabular}




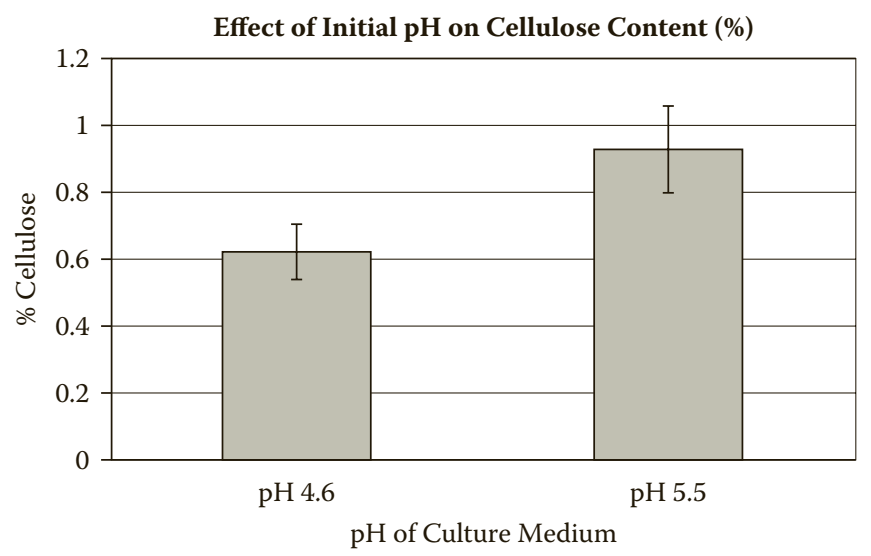

\section{FIGURE 2.9}

Cellulose content (\%) in BNC tubes cultured at $\mathrm{pH} 4.6$ and 5.5. Data are presented as the average \pm standard deviation. Four replicates in each group.

\section{Cellulose Content}

The initial $\mathrm{pH}$ of the culture medium affects the cellulose content in the BNC tubes. The cellulose content was calculated by dividing the dry weight of the $\mathrm{BNC}$ tube by the wet weight of the BNC tube:

Cellulose content $(\%)=($ dry weight BNC tube $/$ wet weight BNC tube $) \times 100$.

We investigated the effect of the initial $\mathrm{pH}$ of the growth media and found that the cellulose content increases during the cultivation period for both $\mathrm{pH}$ 4.6 and $\mathrm{pH}$ 5.5. At day 7, when the tubes were harvested, the highest cellulose content was shown to be in the BNC tubes cultured at pH 5.5 (see Figure 2.9).

\section{Influence of Oxygen Availability on Tube Formation}

Oxygen availability in the medium during culture in a tube bioreactor can be measured using an oxygen probe. This bioreactor is identical to the tube bioreactor with the exception of a side tube that allows for insertion of an oxygen probe. A needle oxygen probe and a Microx TX3 microfiber optic oxygen transmitter were used for the measurements. Oxygen measurements showed that oxygen passes through the silicon tubing and the level increases in the medium, but it drops rapidly to a few percent due to the consumption of oxygen by the bacteria (see Figure 2.10). The decrease was surprisingly fast (within 10 hours). During this time the number of bacteria increases, but no cellulose layer is yet visible. The oxygen level then remains around $2 \%$ for the rest of the culture time, which is usually 7 days. The cellulose tube is visible after 1 day and continues to be formed until day 4 , where no further increase in thickness can be observed. 


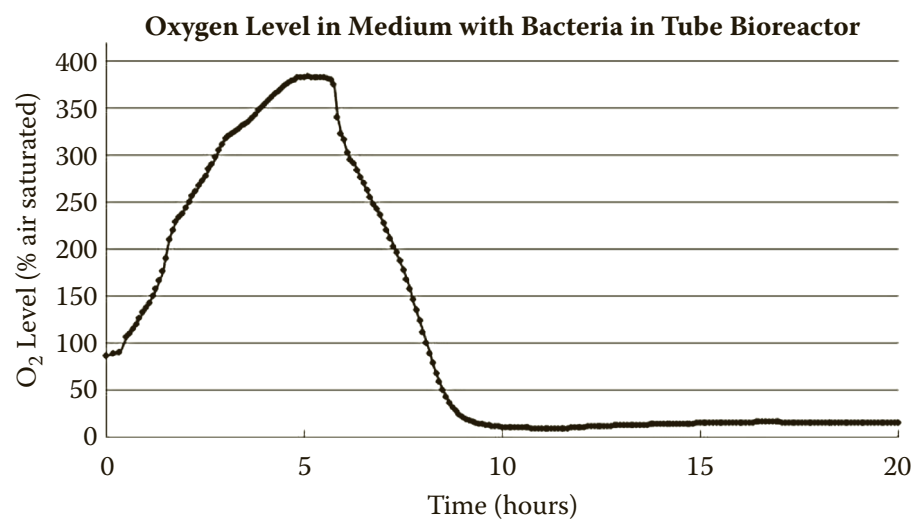

FIGURE 2.10

Oxygen level measurements during BNC tube culture using the tube bioreactor with $100 \% \mathrm{O}_{2}$ supply $(70 \mathrm{~mL} / \mathrm{min})$. Since pure oxygen is used, the oxygen level in the cultivation medium is saturated.

Close to the silicone surface, the bacteria have access to oxygen during cultivation; in the cultivation medium, however, the level of oxygen is very low, which might be due to the fact that a thin layer of cellulose was produced on the silicone surface and that this may act as an oxygen barrier. Thus the oxygen cannot diffuse out into the media. The oxygen limitation in the tube bioreactor may affect the metabolism, since the bacterium is an obligate aerobe. To avoid oxygen limitations and to get more evenly distributed oxygen in the cultivation medium, it would be preferable to use a continuous bioreactor. In a continuous bioreactor, an inflow of new cultivation medium, which is saturated with oxygen, can be used.

\section{Properties and Components of CSL}

The composition of CSL is not fully known and varies between different batches. This is most challenging, as it results in varying growth conditions and therefore a varying quality of the tubes produced. The $\mathrm{pH}$ of CSL is 3.5-4.5 (Liggett and Koffler 1948) and the variation depends on the composition of the CSL batch. Common for all the batches is that the color of CSL is light brown to brown and has a characteristic odor. The major components of CSL are crude proteins (47\%) and lactic acid (26\%) (White and Johnson 2003).

The amino acid composition of CSL has been analyzed and 16-20 different amino acids have been found. Saha and Racine (2010) compared the amino acid content of three different batches (see Table 2.2). In this table, it can be seen that the total amount of amino acids differs quite a lot between different batches (from 39.38 to $76.11 \mathrm{mg} / \mathrm{g}$ ). The highest amounts of amino acids are represented by glutamic acid, proline, alanine, leucine, and arginine (Saha 
TABLE 2.2

Amino Acid Composition of Three Different CSL Batches (Saha and Racine 2010).

\begin{tabular}{lrrr}
\hline Amino Acid & $\begin{array}{r}\text { CSL A } \\
(\mathbf{m g} / \mathbf{g})\end{array}$ & $\begin{array}{r}\text { CSL B } \\
(\mathbf{m g} / \mathbf{g})\end{array}$ & $\begin{array}{r}\text { CSL C } \\
(\mathbf{m g} / \mathbf{g})\end{array}$ \\
\hline Aspartic acid & 3.40 & 1.93 & 0.39 \\
Threonine & 2.40 & 1.23 & 2.42 \\
Serine & 3.07 & 1.59 & 3.11 \\
Aspargine & 3.77 & 1.84 & 2.60 \\
Glutamic acid & 5.45 & 2.44 & 4.49 \\
Glutamine & 1.05 & 0.60 & 0.04 \\
Proline & 9.16 & 4.76 & 7.37 \\
Glycine & 1.59 & 0.83 & 1.70 \\
Alanine & 7.12 & 3.57 & 8.52 \\
Valine & 4.48 & 2.37 & 4.35 \\
Cystine & 0.17 & 0.14 & 0.28 \\
Methionine & 2.29 & 1.24 & 2.39 \\
Isoleucine & 2.22 & 1.30 & 2.63 \\
Leucine & 9.65 & 5.15 & 8.84 \\
Tyrosine & 3.07 & 1.72 & 0.00 \\
Phenylalanine & 4.63 & 2.41 & 3.73 \\
Tryptophan & 0.37 & 0.00 & 0.00 \\
Lysine & 4.22 & 2.27 & 3.54 \\
Histidine & 1.66 & 0.84 & 0.04 \\
Arginine & 6.34 & 3.15 & 5.16 \\
Total & 76.11 & 39.38 & 61.60 \\
\hline & & &
\end{tabular}

and Racine 2010). In another study done in 1948, Cardinal and Hedrick found that amino acids together with ammonia account for more than $95 \%$ of the total nitrogen concentration in the CSL. The highest amino acids presented were alanine, glutamic acid, and arginine (Cardinal and Hedrick 1947). This is in accordance with Saha and Racine (2010), who also demonstrated large amounts of these amino acids.

\section{Conclusion and Future Perspectives}

Many attempts have been made to improve the compatibility and effectiveness of vascular grafts by modifying surface properties by incorporating biologically active substances. Several investigations focusing on increasing endothelial cell adhesion to nonadhesive polymeric biomaterials used for synthetic vascular grafts have been carried out. Precoating with the tripeptide Arg-Gly-Asp (RGD), an amino acid sequence found in many adhesive plasma 
and extracellular matrix proteins, has been used to enhance cell adherence. The binding of cells to the RGD sequence occurs via integrin receptors on the cell membrane.

A great challenge in the development of synthetic blood vessels is to set up a cyclic guanosine monophosphate (cGMP) facility for production of cellulose tubes, and this is relevant for all procedures in the manufacturing process. Regulatory approved product requires preclinical and clinical trials, since there is no "predicate" device on the market. The effectiveness of BNC as vascular grafts shown in preclinical trials is promising for the future use of $\mathrm{BNC}$ as vascular grafts.

\section{Acknowledgments}

We would like to thank the Swedish Foundation for Strategic Research, Vinnova, and the Swedish Research Council for funding the biosynthetic blood vessel program.

\section{References}

Arvidson, S. A., B. T. Rinehart, and F. Gadala-Maria. 2006. Concentration regimes of solutions of levan polysaccharide from Bacillus sp. Carbohyd. Polym. 65:144-149.

Bäckdahl, H., M. Esguerra, D. Delbro, B. Risberg, and P. Gatenholm. 2008. Engineering microporosity in bacterial cellulose scaffolds. J. Tissue Eng. Regen. Med. 2:320-330.

Bäckdahl, H., B. Risberg, and P. Gatenholm. 2011. Observations on bacterial cellulose tube formation for application as vascular graft. Mater. Sci. Eng. C 31:14-21.

Benzamin, M., and B. Rivertz. 1972. Factors affecting hexose phosphorylation in Gluconacetobacter xylinus. J. Bacteriol. 111:325-333.

Bodin, A., H. Bäckdahl, H. Fink, L. Gustafsson, B. Risberg, and P. Gatenholm. 2007. Influence of cultivation conditions on mechanical and morphological properties of bacterial cellulose tubes. Biotechnol. Bioeng. 97:425-434.

Brackmann, C., A. Bodin, M. Akeson, P. Gatenholm, and A. Enejder. 2010. Visualization of the cellulose biosynthesis and cell integration into cellulose scaffolds. Biomacromolecules 11:542-548.

Brown, R. M., Jr., and F. C. Lin. 1990. Multiribbon microbial cellulose. U.S. patent 4,954,439.

Brown, R. M., Jr., A. C. Millard, and P. J. Campagnola. 2003. Macromolecular structure of cellulose studied by second-harmonic generation imaging microscopy. Opt. Lett. 28:2207-2209.

Cardinal, E. V., and L. R. Hedrick. 1947. Microbiological assay of corn steep liquor for amino acid content. J. Biochem. 172:609-612. 
Chang, A. L., J. R. Tuckerman, G. Gonzalez, R. Mayer, H. Weinhouse, G. Volman, D. Amikam, M. Benziman, and M. A. Gilles-Gonzalez. 2001. Phosphodiesterase A1, a regulator of cellulose synthesis in Gluconacetobacter xylinus, is a heme-based sensor. Biochemistry 40:3420-3426.

Cheng, J. X. 2007. Coherent anti-Stokes Raman scattering microscopy. Appl. Spectrosc. 61:197-208.

Chien, L. J., H. T. Chen, P. F. Yang, and C. K. Lee. 2006. Enhancement of cellulose pellicle production by constitutively expressing Vitreoscilla hemoglobin in Acetobacter xylinum. Biotechnol. Prog. 22:1598-1603.

Cook, K., and R. J. Colvin. 1980. Evidence for a beneficial influence of cellulose production on growth of Acetobacter xylinum in liquid medium. Curr. Microbiol. 3:203-205.

Coucheron, D. H. 1991. An Acetobacter xylinum insertion sequence element associated with inactivation of cellulose production. J. Bacteriol. 173:5723-5731.

Czaja, W., D. Romanovvicz, and R. Malcolm Brown, Jr. 2004. Structural investigation of microbial cellulose produced in stationary and agitated cultures. Cellulose 11:403-411.

De Wulf, P., K. Joris, and E. J. Vandamme. 1996. Improved cellulose formation by Gluconacetobacter xylinus mutant limited in (keto)gluconate synthesis. J. Chem. Technol. Biotechnol. 67:376-380.

Dikshit, K. L., and D. A. Webster. 1988. Cloning, characterization and expression of the bacterial globin gene from Vitreoscilla in Escherichia coli. Gene 70:377-386.

Embuscado, M. E., J. S. Marks, and J. N. Bemiller. 1994. Bacterial cellulose I. Factors affecting the production of cellulose by Gluconacetobacter xylinus. Food Hydrocolloid 8:407-418.

Hess, F., C. Jerusalem, B. Braun, and P. Grande. 1985. Three years experience with experimental implantation of fibrous polyurethane microvascular prostheses in the rat aorta. Microsurgery 6:155-162.

Ishida, T., Y. Sugano, T. Nakai, and M. Shoda. 2002. Effects of acetan on production of bacterial cellulose by Acetobacter xylinum. Biosci. Biotechnol. Biochem. 66:1677-1681.

Kirby, A. R., A. P. Gunning, V. J. Morris, and M. J. Ridout. 1995. Observation of the helical structure of the bacterial polysaccharide acetan by atomic force microscopy. Biophys. J. 68:360-363.

Klemm, D., D. Schumann, U. Udhardt, and S. Marsch. 2001. Bacterial synthesized cellulose-artificial blood vessels for microsurgery. Progress in Polymer Science. 26:1561-1603.

Kornmann, H., P. Duboc, I. Marison, and U. von Stockar. 2003. Influence of nutritional factors on the nature, yield, and composition of exopolysaccharides produced by Gluconacetobacter xylinus I-2281. Appl. Environ. Microbiol. 69:6091-6098.

Krystynowicz, A., M. Koziolkiewicz, A. Wiktorowska-Jezierska, S. Bielecki, E. Klemenska, A. Masny, and A. Płucienniczak. 2005. Molecular basis of cellulose biosynthesis disappearance in submerged culture of Gluconacetobacter xylinus. Acta Biochim. Pol. 52:691-698.

Liggett, W. R., and H. Koffler. 1948. Corn steep liquor in microbiology. Bacteriol. Rev. 12:297-311.

Marx-Figini, M., and B. G. Pion. 1974. Kinetic investigation on biosynthesis of cellulose by Gluconacetobacter xylinus. Biochim. Biophys. Acta 338:382-393. 
Matsuoka, M., T. Tsuchida, K. Matsushita, O. Adachi, and F. Yoshinaga. 1996. A synthetic medium for bacterial cellulose production by Acetobacter xylinum subsp. sucrofermentans. Biosci., Biotechnol. Biochem. 60:575-579.

Mikkelsen, D., B. M. Flanagan, G. A. Dykes, and M. J. Gidley. 2009. Influence of different carbon sources on bacterial cellulose production by Gluconacetobacter xylinus strain ATCC 53524. J. Appl. Microbiol. 107:576-583.

Naritomi, T., T. Kouda, H. Yano, and F. Yoshinaga. 1998. Effect of ethanol on bacterial cellulose production in continuous culture from fructose. J. Ferment. Bioeng. 85:598-603.

Nerem, R. M., and D. Seliktar. 2001. Vascular tissue engineering. Annu. Rev. Biomed. Eng. 3:225-243.

Nguyen, V. T., B. Flanagan, D. Mikkelsen, S. Ramirez, L. Rivas, M. J. Gidley, and G. A. Dykes. 2010. Spontaneous mutation results in lower cellulose production by a Gluconacetobacter xylinus strain from Kombucha. Carbohyd. Polym. 80:337-343.

Noro, N., Y. Sugano, and M. Shoda. 2004. Utilization of the buffering capacity of corn steep liquor in bacterial cellulose production by Acetobacter xylinum. Appl. Microbiol. Biotechnol. 64:199-205.

Okajima, K., Y. Matsuda, and K. Kamide. 1991. Study on changes in the degree of polymerization of bacterial cellulose produced by Gluconacetobacter xylinus during its cultivation. Polym. Int. 25:145-151.

Pringsheim, E. G. 1951. The Vitreoscillaceae: a family of colorless, gliding, filamentous organisms. J. Gen. Microbiol. 5:124-149.

Rezaee, A., S. Solimani, and M. Forozandemogadam. 2005. Role of plasmid in the production of Acetobacter xylinum biofilms. Am. J. Biochem. Biotechnol. 1:121-124.

Roberts, E. M., L. K. Hardison, and R. M. Brown, Jr. 1986. Production of microbial cellulose, 1986-07-02. European patent number 0186495.

Ross, P., R. Mayer, and M. Benziman. 1991. Cellulose biosynthesis and function in bacteria. Microbiol. Rev. 55:35-58.

Ross, P., R. Mayer, H. Weinhouse, D. Amikam, Y. Huggirat, and Y. Benziman. 1990. The cyclic diguanylic acid regulatory system of cellulose synthesis in Acetobacter xylinus. J. Biol. Chem. 265:18933-18943.

Saha, B. C., and F. M. Racine. 2010. Effects of pH and corn steep liquor variability on mannitol production by Lactobacillus intermedius NRRL B-3693. Appl. Microbiol. Biotechnol. 87:553-560.

Saxena, I. M., E. M. Roberts, and R. M. Brown, Jr. 1990. Modification of cellulose normally synthesized by cellulose-producing microorganisms. U.S. patent 4,950,597.

Schramm, M., and S. Hestrin. 1954. Factors affecting production of cellulose at the air/liquid interface of a culture of Acetobacter xylinum. J. Gen. Microbiol. 11:123-129.

Setyawati, M. I., L. J. Chien, and C. K. Lee. 2007. Expressing Vitreoscilla hemoglobin in statically cultured Acetobacter xylinum with reduced $\mathrm{O}_{2}$ tension maximizes bacterial cellulose pellicle production. J. Biotechnol. 132:38-43.

Son, H. J., M. S. Heo, Y. G. Kim, and S. J. Lee. 2001. Optimization of fermentation conditions for the production of bacterial cellulose by a newly isolated Acetobacter sp. A9 in shaking cultures. Biotechnol. Appl. Biochem. 33:1-5.

Svensson, A., E. Nicklasson, T. Harrah, B. Panilaitis, D. L. Kaplan, M. Brittberg, and P. Gatenholm. 2005. Bacterial cellulose as a potential scaffold for tissue engineering of cartilage. Biomaterials 26:419-431. 
Tahara, N., M. Tabuchi, K. Watanabe, H. Yano, Y. Morinaga, and F. Yoshinaga. 1997a. Degree of polymerization of cellulose from Gluconacetobacter xylinus BPR2001 decreased by cellulose produced by the strain. Biosci. Biotechnol. Biochem. 61:1862-1865.

Tahara, N., H. Yano, and F. Yoshinaga. 1997b. Two types of cellulose activity produced by a cellulose producing Acetobacter strain. J. Ferm. Bioeng. 83:389-392.

Tsai, P. S., M. Nägeli, and J. E. Bailey. 1996. Intracellular expression of Vitreoscilla hemoglobin modifies microaerobic Escherichia coli metabolism through elevated concentration and specific activity of cytochrome o. Biotechnol Bioeng. 49:151-160.

Valla, S., D. H. Coucheron, and J. Kjosbakken. 1987. The plasmids of Acetobacter xylinum and their interaction with the host chromosome. Mol. Gen. Genet. 208:76-83.

Valla, S., and J. Kjosbakken. 1982. Cellulose-negative mutants of Gluconacetobacter xylinus. J. Gen. Microbiol. 128:1401-1408.

Verschuren, P. G., T. D. Cardona, M. J. Nout, K. D. De Gooijer, and J. C. Van den Heuvel. 2000. Location and limitation of cellulose production by Acetobacter xylinum established from oxygen profiles. J. Biosci. Bioeng. 89:414-419.

Watanabe, K., M. Tabuchi, Y. Morinaga, and F. Yoshinaga. 1998. Structural features and properties of bacterial cellulose produced in agitated culture. Cellulose 5:187-200.

Watanabe, K., and S. Yamanaka. 1985. Effects of oxygen tension in the gaseous phase on production and physical properties of bacterial cellulose formed under static culture conditions. Biosci. Biotechnol. Biochem. 59:65-68.

Wei, B., G. Yang, and F. Hong. 2011. Preparation and evaluation of a kind of bacterial cellulose dry films with antibacterial properties. Carbohyd. Polym. 84:533-538.

White, D. G., and R. M. Brown, Jr. 1989. Prospects for the commercialization of the biosynthesis of microbial cellulose. In: Cellulose and Wood-Chemistry and Technology, ed. C. Schuerch, 573-590. New York: John Wiley \& Sons.

White, P., and L. A. Johnson. 2003. Corn: chemistry and technology, 2nd ed. St. Paul, MN: American Association of Cereal Chemists.

Williams, W. S., and R. E. Cannon. 1989. Alternative environmental roles for cellulose produced by Acetobacter xylinum. Appl. Environ. Microbiol. 55:2448-2452.

Wippermann, J., D. Schumann, D. Klemm, H. Kosmehl, S. Salehi-Gelani, and T. Wahlers. 2009. Preliminary results of small arterial substitute performed with a new cylindrical biomaterial composed of bacterial cellulose. Eur. J. Vasc. Endovasc. Surg. 37:592-596.

Yamanaka, S., K. Watanabe, N. Kitamura, M. Iguchi, S. Mitsuhashi, Y. Nishi, and M. Uryu. 1989. The structure and mechanical properties of sheets prepared from bacterial cellulose. J. Mater. Sci. 24:3141-3145.

Zaborowska, M., A. Bodin, H. Bäckdahl, J. Popp, A. Goldstein, and P. Gatenholm. 2010. Microporous bacterial cellulose as a potential scaffold for bone regeneration. Acta Biomater. 6:2540-2547.

Zhang, H. Y., X. J. Yan, Y. Jiang, and J. Cong. 2010. Development and characteristic of bacterial cellulose for antimicrobial wound dressing. Adv. Mater. Res. 978:152-153. 